\title{
Posterior circulation stroke in a cannabis abuser
}

Sir,

Drug abuse is a risk factor for stroke in the young. We describe a case of a cannabis abuser presenting with a posterior circulation stroke. A 22-year-old right-handed male, with history of cannabis abuse for the last two years presented with sudden limb and gait ataxia, $5 \mathrm{~h}$ after consuming seven cigarettes of cannabis. Neurological examination revealed normal higher mental functions except for inappropriate laughter. He had bilateral cerebellar signs, Deep tendon reflexes were brisk and plantar was extensor bilaterally. Cranial magnetic resonance imaging (MRI) showed infarcts in bilateral cerebellar hemispheres, left temporal lobe and an old infarct in the left occipital lobe [Figure 1]. Magnetic resonance angiography (MRA) revealed non-visualization 


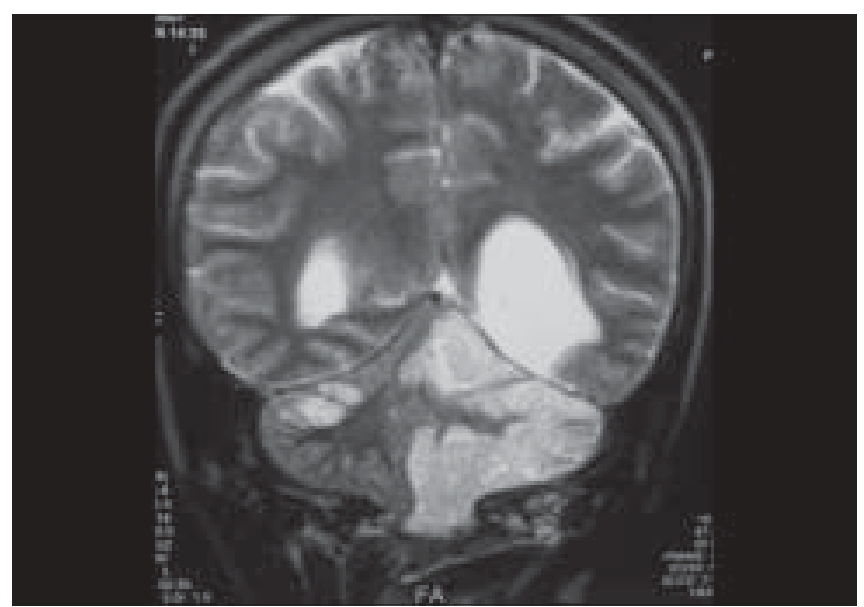

Figure 1: Coronal section MRI BRAIN showing acute infarcts in bilateral cerebellar hemispheres with old infarct in left occipital lobe

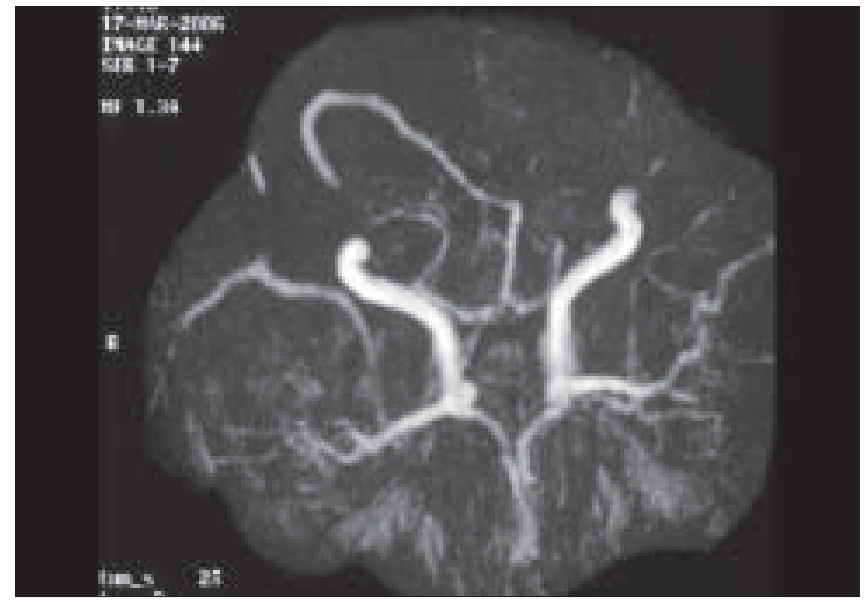

Figure 2: Magnetic resonance angiography of brain showing absent left vertebral artery and attenuated bilateral posterior cerebral arteries

of left vertebral artery and reduced caliber of both the posterior cerebral arteries [Figure 2]. Biochemistry was normal and procoagulant workup and also the workup for young stroke were negative. 2D echo was normal. Patient was put on antiplatelets and at three months follow-up his modified Rankin scale score was 2D echo.

Cocaine, cannabis, amphetamines and marijuana are the common recreational drugs associated with ischemic and hemorrhagic strokes. The side-effects of acute cannabis intoxication include: (1) psychiatric - behavioral abnormalities and increased risk of schizophrenia; ${ }^{[1]}$ (2) cardiovascular - tachycardia, supine hypertension, postural hypotension, myocardial infarction, paroxysmal atrial fibrillation and sudden death:;2] (3) cerebral - hemorrhagic and recurrent ischemic strokes. The mechanisms postulated in cannabis-related strokes are vasospasm, vasculopathy, postural hypotension with abnormal regulation of the cerebral blood flow and paroxysmal atrial fibrillation. ${ }^{[3]}$ A predilection for infarcts in the posterior circulation as seen in our patient has been attributed to a poor autoregulatory mechanism in this vascular bed as compared to the anterior circulation. ${ }^{[4]}$ Toxicological screening for cannabinoid metabolites should be done in young patients with strokes with no apparent vascular risk factors or evidence of dissection. This holds good even in our country with increasing drug abuse among the youth.

\section{Simerpreet Bal, Dheeraj Khurana, Vivek Lal, Sudesh Prabhakar \\ Department of Neurology, Postgraduate Institute of Medical Education of Research, Sector 12, Chandigarh - 160 012, India. E-mail: dherajk@yahoo.com}

DOI: $10.4103 / 0028-3886.48797$

\section{References}

1. Andréasson S, Allebeck P, Engström A, Rydberg U. Cannabis and schizophrenia: A longitudinal study of Swedish conscripts. Lancet 1987;2:1483-6

2. Bachs 1, Morland H. Acute cardiovascular fatalities following cannabis use. Forensic Sci Int 2001;124:200-3.

3. Cooles P, Michaud R. Stroke after heavy cannabis smoking. Postgrad Med J 1987;63:511.

4. Mateo I, Pinedo A, Gomez-Beldarrain M, Basterretxea JM, Garcia-Monco JC. Recurrent stroke associated with cannabis use. J Neurol Neurosurg Psychiatry 2005;76:435-7.

Accepted on 08-02-2009 